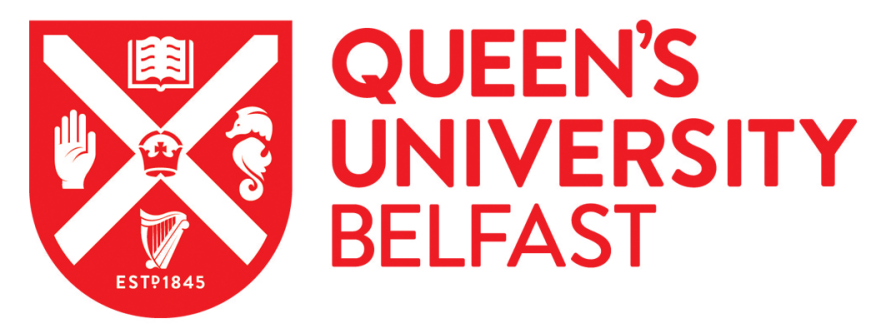

\title{
The effect of increasing fruit and vegetable consumption on overall diet: a systematic review and meta-analysis
}

Fulton, S. L., McKinley, M. C., Young, I. S., Cardwell, C. R., \& Woodside, J. V. (2016). The effect of increasing fruit and vegetable consumption on overall diet: a systematic review and meta-analysis. Critical Reviews in Food Science and Nutrition, 56(5), 802-816. https://doi.org/10.1080/10408398.2012.727917

Published in:

Critical Reviews in Food Science and Nutrition

Document Version:

Peer reviewed version

Queen's University Belfast - Research Portal:

Link to publication record in Queen's University Belfast Research Portal

Publisher rights

Copyright 2014 Taylor \& Francis.

This is an Accepted Manuscript of an article published by Taylor \& Francis in Critical Reviews in Food Science and Nutrition on 13 August 2014, available online: http://www.tandfonline.com/10.1080/10408398.2012.727917.

\section{General rights}

Copyright for the publications made accessible via the Queen's University Belfast Research Portal is retained by the author(s) and / or other copyright owners and it is a condition of accessing these publications that users recognise and abide by the legal requirements associated with these rights.

Take down policy

The Research Portal is Queen's institutional repository that provides access to Queen's research output. Every effort has been made to ensure that content in the Research Portal does not infringe any person's rights, or applicable UK laws. If you discover content in the Research Portal that you believe breaches copyright or violates any law, please contact openaccess@qub.ac.uk. 
The effect of increasing fruit and vegetable consumption on overall diet: a systematic review and meta-analysis

Sharon L. Fulton ${ }^{1}$, Michelle C. McKinley ${ }^{1}$, Ian S. Young ${ }^{1}$, Chris R. Cardwell ${ }^{2}$ and Jayne $^{2}$

\section{Woodside ${ }^{1}$}

${ }^{1}$ Nutrition and Metabolism Group, Centre for Public Health, Queen’s University Belfast, UK.

${ }^{2}$ Cancer Epidemiology and Prevention Research Group, Centre for Public Health, Queen’s University Belfast, UK.

Correspondence address: $\quad$ Dr Jayne Woodside,

Nutrition and Metabolism Group,

Centre for Public Health,

$1^{\text {st }}$ Floor, Institute of Clinical Science B,

Grosvenor Road,

Belfast,

BT12 6BJ,

Northern Ireland,

U.K.

Telephone number:

+442890632585

Fax number:

+442890635900

E-mail address:

j.woodside@qub.ac.uk 


\section{ABSTRACT}

Increasing fruit and vegetable (FV) consumption is associated with reduced risk of major diseases. However, it is unclear if health benefits are related to increased micronutrient intake or to improvements in overall diet profile.

This review aimed to assess if increasing FV consumption had an impact on diet profile. In the systematic review, twelve studies revealed increases in micronutrient intakes, whilst the meta-analysis confirmed macronutrient findings from the systematic review showing no significant difference between the intervention and control groups in energy (kcals) in seven studies (mean difference $=1$ kcals $[95 \% \mathrm{CI}=-115,117] ; P=0.98$ ), significant decreases in total fat (\% energy) in 5 studies (Mean difference $=-4 \%$ [95\% CI $=$ 5, -3]; $P=<0.00001$ ) and significant increases in fibre in 6 studies (Mean difference $=5.36$ grams [95\% CI $=4,7] ; \mathrm{P}=<0.00001$ ) and total carbohydrate (\% energy) in 4 studies (Mean $=4 \%[95 \% \mathrm{CI}=2,5] ; P=<0.00001)$.

In conclusion, results indicate that increased FV consumption increases micronutrient, carbohydrate and fibre intakes and possibly reduces fat intake, with no overall effect on energy intake. Therefore health benefits may act through an improvement in overall diet profile alongside increased micronutrient intakes.

\section{KEYWORDS}

Fruit and vegetables, macronutrient, micronutrient, dietary intake, randomised controlled trials 


\section{INTRODUCTION}

The World Health Organisation (WHO) recommends consumption of at least 400g of fruit and vegetables (FV), equating to 5 portions, per day (World Health Organisation, 1990; Cox et al., 1998; Naska et al., 2000; Whybrow et al., 2006). Evidence suggests an inverse association between consumption of fruit and/or vegetables and risk of non-communicable diseases such as, cardiovascular disease, stroke and several cancers (Dauchet et al., 2005; Dauchet et al., 2006; He et al., 2006; He et al., 2007; WCRF report, 2007). Despite this, the UK intake of FV is below these recommendations, with the National Diet and Nutrition Survey reporting that $86 \%$ of UK adults consume less than 5 portions per day, with $62 \%$ failing to reach 3 portions per day (Henderson et al., 2002; Ashfield-Watt et al., 2003; Carter et al., 2010). It was estimated that, in 2000, low consumption of FV was accountable for 4.9\% of deaths worldwide (Hall et al., 2009).

FV in general contain low levels of protein and fat, moderately high levels of fibre and, mostly in the case of fruit, fairly high levels of carbohydrate (Whybrow et al., 2006). The potential health benefits of FV, however, are usually attributed to the high levels of micronutrients, including antioxidants, carotenoids, flavonoids and vitamin $\mathrm{C}$ which are naturally occurring in these foods (World Health Organisation, 2002). These micronutrients have been suggested to work in a number of potential ways, such as reducing oxidative stress, improving blood pressure and homeostasis regulation and increasing insulin sensitivity (Zino et al., 1997; Appel et al., 1997; Van Duyn \& Pivonka, 2000; Bazzano et al., 2003; Dauchet et al., 2006). Therefore it is postulated that increasing FV consumption has direct health benefits because of the direct biological effects of these nutrients. However, it is also postulated that increased consumption may indirectly improve health by changing the overall balance of the diet, for example, less healthy foods may be displaced by fruit and vegetables. FV are low in energy density and have high water content, allowing individuals to have larger 
portion sizes of these foods, whilst potentially lowering the amount of energy consumed (Svendsen et al., 2007). FV, being rich in fibre, may also promote satiety, thus reducing consumption of other foods that promote weight gain and increase disease risk (Rolls et al., 2004; Slavin, 2005). It is, therefore, unclear whether the health benefits of FV are directly related to the intrinsic properties of these foods and the micronutrients they contain or to the impact of their consumption on overall diet profile.

Therefore the aim of this systematic review and meta-analysis was to assess if increasing consumption of FV had any significant impact on the balance of the overall diet, based on macro- and micronutrient intake data recorded in randomised controlled intervention trials which increased FV consumption.

\section{MATERIALS AND METHODS}

\section{Search Strategy}

Published randomised controlled intervention trials encouraging increased consumption of FV were identified using a search strategy which was developed in Medline and adapted for 5 other search databases - PUBMED, EMBASE, Web of Science (Science Citation Index), Cumulative Index to Nursing and Allied Health Literature (CINAHL) and the Cochrane Library (clinical trials section). The key search terms used in all databases were: "fruit” OR “fruit juices” AND “vegetables” OR "vegetable juices” combined with “intervention” OR “trial” OR “clinical trial”. The search included papers from the earliest record until April 2010. Where possible, the search was limited to adult studies and publications in the English language (Web of Science, CINAHL and the Cochrane Library did not have options for limiting the search to adult studies only, however any studies not conducted in adults were 
excluded in later stages of the review process). Additionally, the bibliographies of included papers were reviewed and any papers found were added.

\section{Study Selection}

For inclusion, publications had to be intervention trials which required adult subjects to increase only FV intake in the diet and to make no other diet or lifestyle changes. Publications were excluded if they were not intervention trials; if the intervention required participants to change other aspects of their diet i.e. to decrease fat intake whilst increasing FV intake; if it was not a free-living study i.e. diets were provided or were specific in nutrient content; or no dietary intake data was presented in the text. The search was carried out by one reviewer (SF) and papers were then reviewed and discarded on initial screening if the reviewer could determine with certainty from the title that the study was not a FV intervention trial or if it was an intervention with a single fruit or vegetable only. Abstracts were then obtained for all other publications and again discarded if the reviewer could determine from the abstract that the study did not meet the criteria. When a paper could not be included/ excluded with certainty from the abstract, the full text of the article was acquired for further evaluation. The suitability of each full text publication was assessed by one reviewer (SF) and checked by a second (JW).

\section{Data Extraction}

Data was extracted from the full text publications by one author (SF) and independently assessed by one further author (JW). Relevant data included the first author's name, year of publication, country of origin, the number of portions subjects had to consume during the intervention, duration of the intervention, if there was a run-in period, if there was a control group, the health status of the subjects, number of subjects, sex, age and BMI of subjects and if dietary advice had been given. Further dietary data was extracted on macro- and 
micronutrient intakes and information on portions of FV consumed. Different measurements of FV intake were reported in studies, for example, grams per day, and portions per day, so to standardise the data, all FV were converted to portions per day, using a standard portion size of 80 g, according to UK Department of Health/ National Health Service guidelines (NHS, 2009). Energy intake was standardised to kilocalories per day after conversion from mega joules (MJ) and kilojoules (kJ). Data from two papers by Djuric et al., (2002 \& 2006) were combined, as both papers presented on the same trial, with one paper presenting data for energy and fat and the other presenting micronutrient data therefore these were displayed in the results tables as one study. If full dietary data from the individual studies was not available in the paper, study authors were not contacted. Any disagreement between authors regarding evaluation of data was resolved through discussion.

\section{Statistical Methods}

For the purposes of the meta-analysis, only studies reporting between-group statistical comparisons were included. Means and standard deviations were taken from the intervention and control groups at the post-intervention time point, and these data were entered into Review Manager Version 5, which produced forest plots showing the pooled effect of the interventions. The heterogeneity of study estimates in each of the forest plots was established using chi-square tests and measured by the $\mathrm{I}^{2}$ statistic (Higgins et al., 2003). Standard random effects models were used to pool the mean difference in outcome between the intervention and control group across the independent studies (DerSimonian \& Laird, 1986) as heterogeneity between studies was anticipated.

\section{RESULTS}


The search, which is summarised in Figure 1, identified 6413 potentially relevant publications. After removal of duplicate publications across the 6 search databases and exclusion on the basis of titles and abstracts, 173 full text publications were retrieved. One hundred and sixty-one of these publications were excluded because: they were not randomised controlled intervention trials $(n=17)$; the intervention goals were not specific to increasing FV only $(n=88)$; the entire diets were provided by the investigators $(n=43)$; subjects were not given free choices of FV or the interventions were very specific $(n=5)$; or no dietary intake data was presented $(n=8)$. Twelve publications were included in the systematic review (although with the combining of the two Djuric papers, mentioned previously, this is presented as eleven papers within the results tables) and seven of these presented data in a suitable format (i.e. reported between-group statistical comparisons of macronutrient intake) to be included in the meta-analysis.

\section{Study Characteristics}

Tables 1 and 2 summarise the study characteristics for all publications which met the inclusion criteria.

Table 1 displays studies which reported between-group difference (i.e. difference between intervention and control groups). The reported baseline FV intakes ranged between 1.9 and 7.3 portions per day, with post-intervention difference between groups ranging between 2.2 and 5.8 portions per day. Four of eight studies used healthy subjects. The mean age of participants included in the trials ranged from 27.8 years to 58.6 years. Six of the eight studies gave dietary advice to subjects, whilst the remaining two studies did not give any advice to subjects. Dietary advice was mainly given by dieticians or study researchers and included ways of incorporating or increasing FV into the diet. 
Table 2 displays studies which reported on within-group change (i.e. post- minus preintervention). The reported baseline FV intakes ranged between 4.0 and 5.4 portions per day, with difference in intake post- minus pre-intervention ranging between 1.9 and 7.1 portions per day. Two of the three studies used subjects with a history of cancer (either a family history or those previously treated for cancer) and one study used obese subjects. The mean age of participants included in the trials ranged from 21 to 68 years. All three studies gave dietary advice to subjects, similar to that given in the between-group studies.

\section{Analysis of Findings for Systematic Review}

Macronutrient Data - Table 3 shows a summary of the results for between-group (intervention vs. control) difference post-intervention. Seven of the eight studies summarised in the table reported on difference in macronutrient intake between groups, the remaining study by Rock et al., (2001) reported micronutrient data only. One study from the seven showed significant increases in energy intake in the intervention compared to the control group, with the remaining studies reporting no significant difference in energy intake in response to increased FV consumption. Four out of the seven studies showed significant decreases in total fat intake, with the three studies measuring saturated fat intake all showing significant decreases post-intervention. Both of the studies which measured monounsaturated fat also found significant decreases. Four of six studies reporting on carbohydrate intake and five of six studies reporting on fibre intake showed significant increases in response to increased FV intake. One of two studies showed significant increases in total sugar intake. Polyunsaturated fat $(n=2)$, starch $(n=1)$ and protein $(n=5)$ intake did not change in response to increased FV intake in any of the studies reporting these nutrients. Most trials included subjects with a BMI of $\leq 25 \mathrm{~kg} / \mathrm{m}^{2}$. Six studies reported body weight data; of these, one study reported a significant increase in body weight (Cox et al., 1998), one study reported a significant decrease in body weight (Svendsen et al., 2007) and four studies reported no 
significant difference in body weight post-intervention (Maskarinec et al., 1999; SmithWarner et al., 2000; Watzl et al., 2005; Whybrow et al., 2006). Examining body weight in relation to energy/ fat intakes showed that 2 studies reporting no significant change in body weight, also reported significant decreases in fat intakes of 8\% (Maskarinec et al., 1999) and 4\% (Smith-Warner et al., 2000), with no significant change in energy intakes. Furthermore the study by Cox et al. (1998) showed significant increases in body weight alongside a nonsignificant decrease in both energy (-24 kcals) and fat (-3\%) intakes. Svendsen et al. (2007) found significant decreases in body weight together with significant decreases in fat intakes of $-4 \%$ and non-significant decreases in energy intake (-213 kcals). Two studies by Watzl et al. (2005) and Whybrow et al. (2006) showed neither significant change in body weight or energy/ fat intakes.

Studies which only presented within-group differences (post- minus pre- intervention) are shown in table 4. Only one study out of three showed significant increases in energy intake post FV intervention. One of three studies reported significant decreases in total fat intake post intervention, with no significant change being found in saturated fat intake in the one study which reported saturated fat. Of the studies which reported on carbohydrate $(n=1)$, protein $(n=1)$ and fibre intakes $(n=2)$ no significant differences were found. BMI or body weight data were not included for any of these trials however one study did report that subjects had significantly increased body weight post-intervention (Djuric et al., 2002 \& 2006) and this study also reported significant increases in energy intakes (+166 kcals) during the intervention, although significant decreases in fat intakes (-2\%) were also reported. Furthermore one study reported significant decreases in body weight post-intervention (Lapointe et al., 2010). Dietary intake data from this study showed decreases in energy intakes (-90 kcals) and fat intakes (-2\%), however these did not reach statistical significance. 
Micronutrient Data - Table 5 shows a summary of studies reporting between-group difference for micronutrient intakes. Of the studies reporting on beta-carotene and vitamin $\mathrm{C}$ (four of four studies each), total carotenoids and vitamin A (one of one studies each), alphacarotene and lutein (two of two studies), and the study by Cox et al. (1998), which reported alpha- and beta-carotene together, all showed significant increases when FV intake was increased. Increases were also seen in the two studies reporting on lycopene and betacryptoxanthin, however only one study for each nutrient showed significant increases, whilst the other study did not reach statistical significance. Similarly for vitamin E, two of three studies showed significant increases.

Table 6 shows a summary of the micronutrient intakes for studies reporting withingroup difference in response to increased FV consumption. Of the two studies reporting on beta-carotene and vitamin C, both showed statistically significant increases. Le Marchand et al. (1994) was the only within-group study to report on alpha-carotene and betacryptoxanthin which showed non-significant increases, as well as lutein, lycopene and total carotenoids all of which showed statistically significant increases. Vitamin E was reported by one study but showed no difference when FV intake was increased.

As the majority of studies reported an increase in micronutrient intake as a result of increased FV consumption, these nutrients were not considered further.

\section{Analysis of Findings for Meta-Analysis}

For the meta-analysis results were pooled from seven of the eleven intervention studies in the systematic review, using only those reporting between-group differences post-intervention, Rock et al (2001) could not be included as only micronutrients were reported in this paper. Energy in kilocalories (Figure 2), carbohydrate reported as either \% food energy (Figure 3) or grams (Figure 4), fat reported as either \% food energy (Figure 5) or grams (Figure 6), 
and fibre (Figure 7) were the nutrients reported by a sufficient number of studies to perform a meta-analysis. There was no evidence of a difference in energy in kilocalories between the intervention and control group when FV intake was increased in the seven studies examined (Mean difference $=1 \mathrm{kcal}$ [95\% CI= -115, 117]; $P=0.98$; Figure 2). Four studies reported on carbohydrate intakes (expressed as \% food energy) and these showed a significant increase in intervention compared to control when FV were increased (Mean $=4 \%[95 \% \mathrm{CI}=2,5]$; $P=<0.00001$; Figure 3), however the two studies reporting carbohydrate intake in grams, showed no significant difference (Mean= 12 grams [95\% CI= -25, 49]; $P=0.54$; Figure 4). In the five studies reporting on fat intake, there was a significant decrease in fat, reported as \% food energy, in the intervention group compared with the control group (Mean difference= $4 \%[95 \% \mathrm{CI}=-5,-3] ; P=<0.00001$; Figure 5). In the three studies, which reported fat intake in grams, when FV intake was increased there was a trend towards a decrease in fat intake (Mean difference $=-9$ grams $[95 \% \mathrm{CI}=-23,5] ; P=0.21$ ). Finally, in the six studies reporting on fibre intake, there was a significant increase in the intervention group compared with the control group (Mean difference $=5$ grams $[95 \% \mathrm{CI}=4$, 7]; $P=<0.00001$ ). There was little evidence of heterogeneity between studies, for energy, carbohydrate as \% food energy, carbohydrate in grams, fat as $\%$ food energy, fat in grams, or fibre $\left(\mathrm{I}^{2}=33 \%,=41 \%,=0 \%\right.$, $=0 \%,=43 \%$ and $=27 \%$, respectively) .

\section{DISCUSSION}

This study has shown, using systematic review and meta-analysis techniques, that some significant improvements can be seen in the overall diet profile when FV intakes are increased. These improvements are seen in both macro- and micronutrient intakes.

\section{Macronutrient Profile}


Our macronutrient results show that increasing FV intake leads to an increase in carbohydrate and fibre intakes. Our data also suggest that subjects may have been substituting the higher fat foods in their diet for the additional FV, with apparent decreases being observed in total, saturated and monounsaturated fat intakes, expressed as \% food energy. Previous literature has suggested that individuals with higher FV consumption have reduced intakes of meat (Elmstahl et al., 1999; Smith-Warner et al., 2000), although our data showed no significant changes in protein intake when FV were increased, and protein was therefore not included in the meta-analysis. We were unable to examine specific differences in food habits in order to formally assess whether individuals are displacing other food groups in the diet when FV intakes are increased, and what foods are typically affected. Specific differences at the food level are worthy of further investigation, as is what impact these changes have on a broader spectrum of macronutrients and the possible beneficial/detrimental effects of this spectrum of macronutrient changes on health.

\section{Micronutrient Profile}

The majority of micronutrients increased significantly across all studies in the systematic review, and therefore further examination by meta-analysis was not carried out. In a western diet, FV intakes tend to be low (Lock et al., 2005; Hall et al., 2009), and consumers are increasingly using supplements which contain these essential micronutrients (Lui, 2003; Hoare et al., 2004; Velicer \& Ulrich, 2008; Hutchinson et al., 2010), however it is not known whether supplements contain similar health benefits or if increasing levels of micronutrients in this way is safe (Miller et al., 2005; Bjelakovic et al., 2010; Mursu et al., 2011). This review suggests that by attempting to increase micronutrient consumption through

supplement use rather than FV intake, extra health benefits in terms of changes in macronutrient and fibre intake may also be missed. 


\section{Strengths \& Limitations}

To our knowledge, this is the first systematic review and meta-analysis examining FV consumption and differences in macronutrient and micronutrient intake. The search strategy was systematic and broad search terms ensured that as many relevant papers as possible were retrieved. This review also has several limitations. Firstly, the small number of papers $(n=7)$ included in the meta-analysis may mean that definite conclusions cannot be drawn. Furthermore, because of the small number of papers included, regression analysis to examine the magnitude of changes per portion increase of FV could not be carried out. The Cochrane handbook recommends no less than 10 papers in a meta-regression, otherwise conclusions drawn may be deceptive (Higgins, 2011). Secondly the potential of over- or under-reporting of various food groups by study subjects will have affected dietary intake data; this is a problem in any study of dietary intake (Kristal et al., 1994; Herbert et al., 1995; Miller et al., 2008), with participants more likely to underreport their energy intake and over-report fruit and vegetable intake. The majority of energy/ fat intakes did not correlate with changes in body weight in the studies reporting on these findings, with some studies acknowledging that underreporting was likely (Cox et al., 1998; Maskarinec et al.1999). Only one study by Svendsen et al. (2007) showed consistent results with significant decreases in body weight alongside significant decreases in fat intake. Furthermore it is probable that accuracy of reporting is not the only limitation of dietary data collection but the likelihood that keeping a record of dietary intakes may also influence choices and therefore alter usual intakes (Djuric et al., 2006). Thirdly, in four of the eight between-group studies and in all three of the withingroup studies, subjects had baseline FV intakes > four portions per day; this is greater than population averages reported in the literature (Henderson et al., 2002; Ashfield-Watt et al., 2003; Carter et al., 2010), therefore these individuals had a relatively healthy diet and lifestyle prior to inclusion in the studies, and cannot be said to be representative, and this may 
have affected the dietary choices they made when increasing FV consumption. These subjects may have been of a higher socioeconomic status, been more interested in their health, and therefore more likely to participate in intervention studies. Finally, there was heterogeneity between the studies, in relation to the inclusion of potatoes in some studies as a portion of FV, differences in guidance given on FV choices, the duration of the interventions and differences in the dietary advice and support which was given to study participants and this may have affected our findings.

\section{Conclusions}

In conclusion, this systematic review and meta-analysis has shown that by increasing FV consumption, micronutrient intake increases, energy intake stays the same, carbohydrate and fibre intake seem to increase, whilst total fat may decrease. This is likely to lead to improvements in the overall diet profile. Thus the increased consumption of FV may not only directly contribute to health benefits through increased micronutrient intake, but may also lead to a potential increase in carbohydrate and fibre intakes and a possible reduction in fat intake. What is unclear, and has not been possible to deal with in this review, is if these differences in macronutrient and fibre intakes are due to the inclusion of extra FV over and above the usual diet, or due to displacement of less healthy foods from the diet. The lack of observed difference in energy intake would imply that at least some substitution is taking place.

Further intervention studies are needed, to determine how people incorporate extra FV into their diet in a free-living situation, and what impact this has on overall dietary profile. For researchers conducting FV intervention studies it may be beneficial to try to incorporate 
an examination of the impact of FV increase on broader changes at the food and nutrient level. 


\section{REFERENCES}

Appel, L. J., Moore, T. J., Obarzanek, E., Vollmer, W. M., Svetkey, L. P., Sacks, F. M., Bray, G. A., Vogt, T. M., Cutler, J. A., Windhauser, M. M., Lin, P. H., and Karanja, N. (1997). A clinical trial of the effects of dietary patterns on blood pressure. DASH Collaborative Research Group. N Engl J Med. 336: 1117-1124.

Ashfield-Watt, P. A., Welch, A. A., Day, N. E., and Bingham, S. A. (2003). Is 'five-a-day' an effective way of increasing fruit and vegetable intakes? Public Health Nutr. 7: 257-261.

Bazzano, L. A., Serdula, M. K., and Liu, S. (2003). Dietary intake of fruits and vegetables and risk of cardiovascular disease. Curr Atheroscler Rep. 5: 492-499.

Bjelakovic, G., Nikolova, D., Gluud, L. L., Simonetti, R. G., and Gluud, C. (2010). Antioxidant supplements for prevention of mortality in healthy participants and patients with various diseases. Cochrane Database Syst Rev. (2): CD007176.

Carter, P., Gray, L. J., Troughton, J., Khunti, K., and Davies, M. J. (2010). Fruit and vegetable intake and incidence of type 2 diabetes mellitus: systematic review and metaanalysis. BMJ. 341: c4229.

Cox, D. N., Anderson, A. S., Reynolds, J., McKellar, S., Lean, M. E., and Mela, D. J. (1998). Take Five, a nutrition education intervention to increase fruit and vegetable intakes: impact on consumer choice and nutrient intakes. Br J Nutr. 80: 123-131.

Dauchet, L., Amouyel, P., and Dallongeville, J. (2005). Fruit and vegetable consumption and risk of stroke. Neurology. 65: 1193-1197.

Dauchet, L., Amouyel, P., Hercberg, S., and Dallongeville, J. (2006). Fruit and Vegetable Consumption and Risk of Coronary Heart Disease: A Meta-Analysis of Cohort Studies. The Journal of Nutrition. 136: 2588-2593.

DerSimonian, R., and Laird, N. (1986). Meta-Analysis in Clinical Trials. Elsevier. 7 (3): 177188.

Djuric, Z., Poore, K. M., Depper, J. B., Uhley, V. E., Lababidi, S., Covington, C., Klurfeld, D. M., Simon, M. S., Kucuk, O., and Heilbrun, L. K. (2002). Methods to increase fruit and vegetable intake with and without a decrease in fat intake: compliance and effects on body weight in the nutrition and breast health study. Nutr Cancer. 43: 141-151.

Djuric, Z., Ren, J., Mekhovich, O., Venkatranamoorthy, R., and Heilbrun, L. K. (2006). Effects of High Fruit-Vegetable and/or Low-Fat Intervention on Plasma Micronutrient Levels. J Am Coll Nutr. 25: 178-187.

Elmstahl, S., Holmqvist, O., Gullberg, B., Johansson, U., and Berglund, G. (1999). Dietary patterns in high and low consumers of meat in a Swedish cohort study. Appetite. 32: 191-206.

Hall, J. N., Moore, S., Harper, S. B., and Lynch, J. W. (2009). Global Variability in Fruit and Vegetable Consumption. Am J Prev Med. 36: 402-409.e5. 
He, F. J., Nowson, C. A., and MacGregor, G. A. (2006). Fruit and vegetable consumption and stroke: meta-analysis of cohort studies. The Lancet. 367: 320-326.

He, F. J., Nowson, C. A., Lucas, M., and MacGregor, G. A. (2007). Increased consumption of fruit and vegetables is related to a reduced risk of coronary heart disease: meta-analysis of cohort studies. J Hum Hypertens. 21: 717-728.

Hebert, J. R., Clemow, L., Pbert, L., Ockene, I. S., and Ockene, J. K. (1995). Social Desirability Bias in Dietary Self-Report May Compromise the Validity of Dietary Intake Measures. Int J Epidemiol. 24: 389-398.

Henderson, L., Gregory, J., and Swan, G. (2002). National Diet and Nutrition Survey: adults aged 19 to 64 years. Types and quantities of foods consumed. Office for National Statistics, London, UK.

Higgins, J. P. T., Thompson, S. G., Deeks, J. J., and Altman, D. G. (2003). Measuring inconsistency in meta-analyses. BMJ. 327: 557-560.

Higgins, J. P. T., and Green, S. (2011). Cochrane Handbook for Systematic Reviews of Interventions. Available online: www.cochrane-handbook.org [accessed December 6, 2011].

Hoare, J., Henderson, L., Bates, C. J., Prentice, A., Birch, M., Swan, G., et al. (2004). The National Diet and Nutrition Survey: Adults aged 19 to 64 years: Summary Report. Office for National Statistics, London, UK.

Hutchinson, J., Burley, V. J., Greenwood, D. C., Thomas, J. D., and Cade, J. E. (2010). Highdose vitamin $\mathrm{C}$ supplement use is associated with self-reported histories of breast cancer and other illnesses in the UK Women's Cohort Study. Public Health Nutr. 14: 768-777.

Kristal, A., Beresford, S., and Lazovich, D. (1994). Assessing change in diet-intervention research. Am J Clin Nutr. 59: 185S-189S.

Lapointe, A., Weisnagel, S. J., Provencher, V., Begin, C., Dufour-Bouchard, A. A., Trudeau, C., and Lemieux, S. (2010). Using restrictive messages to limit high-fat foods or nonrestrictive messages to increase fruit and vegetable intake: what works better for postmenopausal women? Eur J Clin Nutr. 64: 194-202.

Le Marchand, L., Hankin, J. H., Carter, F. S., Essling, C., Luffey, D., Franke, A. A., Wilkens, L. R., Cooney, R. V., and Kolonel, L. N. (1994). A pilot study on the use of plasma carotenoids and ascorbic acid as markers of compliance to a high fruit and vegetable dietary intervention. Cancer Epidemiol Biomarkers Prev. 3: 245-251.

Liu, R. H. (2003). Health benefits of fruit and vegetables are from additive and synergistic combinations of phytochemicals. Am J Clin Nutr. 78: 517S-520S.

Lock, K., Pomerleau, J., Causer, L., Altmann, D. R., and McKee, M. (2005). The global burden of disease attributable to low consumption of fruit and vegetables: implications for the global strategy on diet. Bull World Health Organ. 83: 100-108. 
Maskarinec, G., Chan, C. L. Y., Meng, L., Franke, A. A., and Cooney, R. V. (1999). Exploring the Feasibility and Effects of a High-Fruit and -Vegetable Diet in Healthy Women. Cancer Epidemiol Biomarkers Prev. 8: 919-924.

Miller, E. R., Pastor-Barriuso, R., Dalal, D., Riemersma, R. A., Appel, L. J., and Guallar, E. (2005). Meta-Analysis: High-Dosage Vitamin E Supplementation May Increase All-Cause Mortality. Annals of Internal Medicine. 142: 37-46.

Miller, T. M., Abdel-Maksoud, M. F., Crane, L. A., Marcus, A. C., and Byers, T. E. (2008). Effects of social approval bias on self-reported fruit and vegetable consumption: a randomized controlled trial. Nutr J. 7: 18.

Mursu, J., Robien, K., Harnack, L. J., Park, K., and Jacobs, D. R. (2011). Dietary supplements and mortality rate in older women: The IOWA Women's Health Study. Arch Intern Med. 171 (18): 1625-1633.

Naska, A., Vasdekis, V. G. S., Trichopoulou, A., Friel, S., Leonhäuser, I. U., Moreiras, O., Nelson, M., Remaut, A. M., Schmitt, A., Sekula, W., Trygg, K. U., and Zajkás, G. (2000). Fruit and vegetable availability among ten European countries: how does it compare with the ‘five-a-day' recommendation? Br J Nutr. 84: 549.

National Health Service (NHS). (2009). 5 A DAY portion sizes. Available online: http://www.nhs.uk/LiveWell/5ADAY/Pages/5ADAYhome.aspx [accessed June 10, 2011].

Rock, C. L., Moskowitz, A., Huizar, B., Saenz, C. C., Clark, J. T., Daly, T. L., Chin, H., Behling, C., and Ruffin Iv, M. T. (2001). High Vegetable and Fruit Diet Intervention in Premenopausal Women with Cervical Intraepithelial Neoplasia. J Am Diet Assoc. 101: 11671174.

Rolls, B. J., Ello-Martin, J. A., and Tohill, B. C. (2004). What can intervention studies tell us about the relationship between fruit and vegetable consumption and weight management? Nutr Rev. 62: 1-17.

Slavin, L. J. (2005). Dietary fiber and body weight. Nutrition. 21: 411-418.

Smith-Warner, S. A., Elmer, P. J., Tharp, T. M., Fosdick, L., Randall, B., Gross, M., Wood, J., and Potter, J. D. (2000). Increasing Vegetable and Fruit Intake: Randomized Intervention and Monitoring in an At-Risk Population. Cancer Epidemiol Biomarkers Prev. 9: 307-317.

Svendsen, M., Blomhoff, R., Holme, I., and Tonstad, S. (2007). The effect of an increased intake of vegetables and fruit on weight loss, blood pressure and antioxidant defense in subjects with sleep related breathing disorders. Eur J Clin Nutr. 61: 1301-1311.

Van Duyn, M. A. S. and Pivonka, E. (2000). Overview of the Health Benefits of Fruit and Vegetable Consumption for the Dietetics Professional: Selected Literature. J Am Diet Assoc. 100: 1511-1521.

Velicer, C. M. and Ulrich, C. M. (2008). Vitamin and Mineral Supplement Use Among US Adults After Cancer Diagnosis: A Systematic Review. J Clin Oncol. 26: 665-673. 
Watzl, B., Kulling, S. E., Möseneder, J., Barth, S. W., and Bub, A. (2005). A 4-wk intervention with high intake of carotenoid-rich vegetables and fruit reduces plasma Creactive protein in healthy, nonsmoking men. Am J Clin Nutr. 82: 1052-1058.

Whybrow, S., Harrison, C. L., Mayer, C., and James Stubbs, R. (2006). Effects of added fruits and vegetables on dietary intakes and body weight in Scottish adults. Br J Nutr. 95: 496-503.

World Cancer Research Fund \& American Institute for Cancer Research. (2007). Food, Nutrition, Physical Activity, and the Prevention of Cancer: A Global Perspective. American Institute for Cancer Research, Washington, DC.

World Health Organisation. (1990). Diet, Nutrition and the Prevention of Chronic Diseases. World Health Organisation, Geneva, Switzerland.

World Health Organisation. (2002). The World Health Report: Reducing Risks, Promoting Healthy Life. World Health Organisation, Geneva, Switzerland.

Zino, S., Skeaff, M., Williams, S., and Mann, J. (1997). Randomised controlled trial of effect of fruit and vegetable consumption on plasma concentrations of lipids and antioxidants. BMJ. 314: 1787. 